\title{
Virtual Reality Mobile Application Development with Scrum Framework as a New Media in Learning English
}

\author{
https://doi.org/10.3991/ijim.v15i08.19923
}

\author{
Albert Yakobus Chandra $\left({ }^{凶}\right)$, Putri Taqwa Prasetyaningrum, Ozzi Suria \\ Universitas Mercu Buana Yogyakarta, Bantul, Indonesia \\ albert. ch@mercubuana-yogya.ac.id \\ Paulus Insap Santosa, Lukito Edi Nugroho \\ Universitas Gadjah Mada Yogyakarta, Yogyakarta, Indonesia
}

\begin{abstract}
Scrum software development has brought new ideas and tools in the software development industry. This study is a finding that the scrum can be a guideline for building mobile-based Virtual Reality applications as a new medium for learning English that is still conventional and has not applied technology to support the teaching and learning process of learning English. Scrum Software provides a framework for managing the iterative and incremental process for building VR applications. The results of this study indicate that a series of Sprint plans contained in the Scrum method have a positive impact and affect the quality of virtual reality mobile application games in English learning and also reveal the theoretical and practical implications that repeated feedback has a moderating effect on the relationship between Sprint planning and quality in VR games.
\end{abstract}

Keywords - Scrum, Virtual Reality, Education, C\#, Mobile learning, Unity3D, Game Development

\section{Introduction}

With the development of technology, people are increasingly dependent on the use of software in their daily routine in various fields, especially in education. The growth of the software development industry is introducing many frameworks and software tools for making and developing and testing more efficient. One of the major innovations in software development methodologies in recent years is the introduction of scrum development. The basic aim of software development is to provide high-quality and fast software to end customers. Research has shown that the use of Scrum in a project can produce significant benefits[1], and its use is not limited to local projects [2].

In this study tried to implement the Scrum method to build a mobile-based virtual reality application for learning English with the background that the emergence of mobile learning technology into teaching and learning has brought new challenges for educators and students. They are faced with an understanding of the complexities and 
concepts of learning[3]. In recent years, virtual reality (VR) has experienced professional development in the gaming field. It plays a very important role in the teaching process, thus providing an attractive way of obtaining information[4][5]. The mobile phone is suitable for implementing VR application because it is a very significant and wonderful communicative tools used for different age groups especially young generation , because of their multimodality, affordability, efficiency, cheaper, more easily accessible and portability to curriculum delivery[6][7].

Many students need a fast response related to their education, especially in English lessons, because there are still many students who don't really understand English, so research on how software development using Scrum can affect the making of mobile based-learning applications is more important to improve the quality of education provided. This mobile game-based VR software application is designed to enhance the experience and interaction of students in learning English, the results of which are in line with the studies by Troussas et al.[8], Gao et al. [9] Siegle et al.[10] Integrating gaming and VR into mobile language learning enhances calculating student interactions and provides them with a unique experience. Education mobile learning greatly contributes to education in students by providing access to educators and students to improve the quality of education provided. However, the use of mobile devices in learning is a panacea[11]. Many researchers emphasize the need to consider learning necessary and preferences when creating educational applications. Thus, the mobile learning application level needs to be excluded. In this study, an insight into how Scrum provides guidelines through several sprint stages to build virtual reality applications that have been adapted to the needs, especially for senior educators who find it difficult to apply technology, so it is important for application developers to adapt the requirement and convenience of people with various ages. Dorouka et al. [12] Zydney et al.[13], and Green et al.[14], the research on the field of mobile learning and education can act as a suggestion to upgrade the quality of education in various other social groups based not only on their specific characteristics, but also for all students in general. In line Kacetl et al. [15], Elaish et al. [16], stated that mobile-learning is an important feature of education because it is a great thing in getting a huge opportunity and step forward, and it must be supported especially by the benefits that language learning brings. It can increase students' cognitive capacity, student motivation to learn in both formal and informal settings, student autonomy and self-confidence, and the fact that this learning method can promote personalized learning and help lowachieving students achieve their learning goals. Recently, the shift in learning due to the spread of the COVID-19 virus has been carried out online in many countries making the need for mobile learning closer and faster[11]. Therefore, the use of Scrum is needed in the development of virtual reality applications because in the Scrum method, cutting edge development movements can be quickly coded and tested using and errors are easy to fix. The combination of the Scrum Method in Virtual Reality Games is a new attempt in the software development field. The output of this study can be guided to researchers who are interested in adopting Scrum in software development. The main advantage of applying the Scrum method in application development is the innovation in the Scrum process which is designed to encourage a limited and short cycle time which focuses on the requirements needed in learning English and has a 
high priority to include faster and stakeholder reviews during the application creation process. This study is focused on the development of virtual reality in the field of education that has been existed before, and how to compile a Scrum life cycle guidelines for the development of Virtual Reality from the stages of the development and implementation, especially in learning English. This game is expected to increase students' motivation and insight in learning then problems caused by a lack of understanding of the material, boredom, and decreased learning can be reduced.

\section{Related Work}

Virtual reality is an adaptation of three-dimensional media through one virtual reality which has three principles of immersion, interaction, and VR users engage with the environment, offering a very high potential in education with more interesting and innovative learning ways[17]. Most of the research related to virtual reality systems using the Scrum method has been carried out. Murat et al.[18] Virtual reality has used to train software practitioners about daily scrum meetings. The goal is to create a virtual environment with virtual characters that will enhance the learning experience of software professionals. Research takes to transform text-based learning into interactive forms that offer engaging experiences by integrating virtual characters who act like human participants and using daily scrum meetings for software project development.

Dina et al. [19] stated that Scrum has had a positive effect on Virtual reality software development of communication, transparency and flies. Demo using virtual reality makes it easy for everyone to get information and understand status in other departmental projects. The majority of Managers report positive effects on productivity, flexibility, and quality when using Scrum in virtual reality projects. Furthermore, Natalia et al. [20] in their research 3D laboratory simulator is applied to perform virtual laboratory work and learn the necessary skills remotely. The practice has shown that after working in a virtual environment, students work with real laboratory reagents and equipment correctly and accurately and describe the intellectual complexes created using 3D modelling. In application development purposed using the Scrum method to be applicable in the conditions of use in project training which must involve a particular game master specialist. The master game is expected to be able to carry out an in-depth methodological study of human behaviour in a virtual reality environment, to implement all possible student interactions with the virtual space elements used. Bin et al. [21] investigates how virtual reality technology can improve the user's mood for a driving simulator with Scrum. This research outlines a field of mobile learning that addresses the main issues identified covering the various challenges of refugee education, how they use smart mobile devices and the effects of mobile learning on students.

In this study, the principle of technical solutions is different from the previous research, especially given the diversity of VR applications with different public targets, as observed in the previous subsection. The new aspects to be developed in this study are visualization displays, game typology, and game machines. The main benefit of 
this game is to inspire students to learn English. This study is expected to provide new guidelines in the development of Virtual Reality games, with the Development Life Cycle Scrum model offered, and becomes an innovation for educators and students to utilize virtual reality media as new media in learning English.

\section{$3 \quad$ Literature Reviews}

\subsection{Virtual reality}

The concept of the virtual reality crisis was a novelty in the technology world in the early 1990s of speculation about its potential already existed [22] Virtual Reality has been represented as immersive multimedia or computer simulation reality that replicates objects in the surrounding environment by simulating physical presence visually in the real so that it allows users to be reliable in that world. It provides a real visual experience that will be simulated through a stereophonic viewer or computer environment. It is a technology that allows a person to simulate factual simulations of a certain object using a computer that can build a 3D atmosphere so that the user is physically involved. The aim of it is to create experiences that make users feel in a virtual world and also provides opportunities to increase the relevant physical interactions, Thus, that users will be immersed in the virtual world [23]. This system is usually also used in designing a building object such as infrastructure development, manufacturing, and even used by ordinary people to carry out the activities mentioned in the real world [24][25]. The emergence of virtual reality technology not only increases the penetration and application of technology, but also brings a new model in learning methods English by applying the concept of games thus that it will attract students to enter. Its technology was introduced as a new form of media consisting of placement, virtual English learning experiments, skills training, interactive use of Virtual Reality scenes, imagery, and full mobilization of student learning initiative and creativity, to develop students' knowledge-building systems. Its technology includes dualsensing interactive technology, control science, simulation environments, simulation systems, high-resolution display techniques, visual systems, the use of psychology, computer graphics, mathematics, and many other disciplines to produce 3D Virtual Reality environments[26].

\subsection{Mobile learning}

Mobile learning is a new way to access learning content using mobile devices. Mobile game-based learning has become a common solution in recent literature because it can enhance student learning in a fun way[27]. Mobile devices with touch screens are the most popular among young people and the current trend is developing very rapid[5] because they can easily access the internet network and access anywhere[28]. Mobile learning is a type of learning method that offers students, independent of time and place, the mobile learning becomes an applied innovation[29][30]. Mobile learning, or M-learning, can be an educational interaction deliv- 
ered via mobile technology as a type of learning resource, learning experiences with other students, and collaborating together in problem-solving [31]. The students desire on practice-oriented learning content rather than memorizing facts[32]. It is not just about using mobile devices to support learning, but also includes all activities that can occur in a circle between educators, learning theory, students, environment, anyone, anywhere, and learning anytime[33]. The main benefit of learning using a mobile device is that it allows students to be in a suitable place and time, so they can experience a pleasant learning environment, wherever it is.

\subsection{Virtual reality in game education}

VR has become one of the important technologies discussed usage and the differences that can achieve huge benefits in the real world[34]. Game educational is a model of the game that is given educational content to provide students with learning experiences in these games. Game-based learning introduces an interactive and innovative way of learning that comes from the use of computer games in that there is educational value. The main purpose of developing an educational game and training simulator to attract children to stay focused during the study session[35] and provides multimedia elements such as audio and animation. A literature review has explored various themes of learning outcomes, instructional design, benefits of education, advantages and challenges of VR in education. The review in[36] related findings to the development of research on the use of VR, AR, and MR technology education in presenting a review of findings that are aligned with the themes of attitude, motivation, interaction, and performance or learning outcomes which is followed by problem thinking, collaboration and communication. Research performed by[23] focus on that using VR allows students to imagine places, objects, or even situations that they have never accessed before and into a new and more innovative VR component that provides. The research was conducted by[37] VR is very beneficial for many fields of activity, including education. It applications in education allow students to gain the experience they would not have gotten in real life and learn by doing and living. Therefore, virtual reality is an important innovation for the future in the field of an educational environment. Nevertheless, using VR in a classroom could have some challenges to face. As stated in [38] One of them is a premium account is required to get full facilities, and the challenge here is the ability of an institution to buy the license needed to use it in classroom learning.

\subsection{Unity 3D}

Unity 3D is a cross-platform based game engine and used to build a game that uses on several different operating system devices such as computers, iPhones, Androids, PS3, IOS, Windows, macOS X, and even X-BOX 360. Unity is an integrated tool that is usually used such functions as rendering engine, physical engine, script engine, lighting mapping, scene management, game development, building architecture, and other simulations[39]. It can process data such as three and two-dimensional objects, object structure, audio, and so on. The advantage of this unity engine is that it pro- 
vides a set of tools for two types of graphic models, namely $2 \mathrm{~d}$ and $3 \mathrm{D}$. The Unity engine is more focused on creating $3 \mathrm{D}$ graphics.

As stated by [40] in their research, Software development is done via the Unity engine thus that model details are identical and match real objects. Unity Engine has a complete framework for professional system development. The core system of this engine uses several programming language options, including $\mathrm{C}$ \#, boo, and javascript, making it easier to use for every update. The Unity $3 \mathrm{~d}$ editor provides several tools to simplify development, namely the Terrain Creator and Unity Tree for vegetation creation, and Terrain for the programming process. Xinqi Liu et al. [41] using Unity $3 \mathrm{D}$ to the development of software applications that the Vuforia SDK is managed for computers and captures 3D planar images in real-time through the camera window that adjusts the position of objects in the camera background. Unity also supports the development of third-party software plugins, and there is an asset store itself that provides a variety of additional plugins for game developers, from developers, by developers, and for developers. In this technology, unity3D and VR were chosen because there are techniques to improve student learning. Among them are improving the development of student spatial thinking skills, improving communication, and increasing student learning motivation. VR technology has been presented as an efficient and innovative paradigm for education[42].

\subsection{C\# programming language}

In 2000, .NET (dot NET) revolutionized the programming language for developing Web and Windows applications[43]. C \# (pronounced C-Sharp) was developed by a team called Microsoft R\&D, led by Scott Wiltamuth and Anders Hejlsberg. Microsoft developed $\mathrm{C}$ \# as the primary language on the .NET platform. Java and C \# syntax inherits and features from $\mathrm{C}, \mathrm{C}++$, but $\mathrm{C}$ \# is more similar to the " $\mathrm{C}$ family"[44]. It is widely used for building virtual $3 \mathrm{D}$, as stated by[45] in their research that $\mathrm{C}$ \# programming language is used by students for graphic user interface (GUI) to build virtual $3 \mathrm{D}$ views, by understanding the concept and mastering $\mathrm{C} \#$ programming will be able to control the transformation of 3D game objects in different coordinate systems. Furthermore, Laura J et al. [46] used C \# programming language in biology for computational modelling, virtual worlds used to manipulate, and describe chemical structures in immersive and collaborative 3D environments. It is a modern, simple, objectoriented, type-safe, and user-friendly programming language, coupled with fast execution, and high security. One of the functions of the $\mathrm{C} \#$ language is object-oriented data processing that provides good flexibility.

\subsection{Scrum}

A Scrum is a software development framework that implements agile and flexible development that is activator-based on teamwork with complexity for a process that is volatile[47]. It begins with planning, then a daily scrum session, and ends with a retrospective meeting. It aims to identify and solve problems that arise. In particular, the daily scrum meetings will provide feedback on project status and opportunities to fix 
problems as they arise, and are useful for measuring individual productivity on a daily basis. Scrum is used for software development projects and managing application development and divided into several sprints[48]. The use of scrum is the most popular because of its high productivity[49]. Therefore, the Scrum method was chosen to produce a product that suits their needs because they can adapt to changes necessary during the application development process. There are three roles in Scrum such as Product Owner, Scrum Master, and the Scrum Team[50].

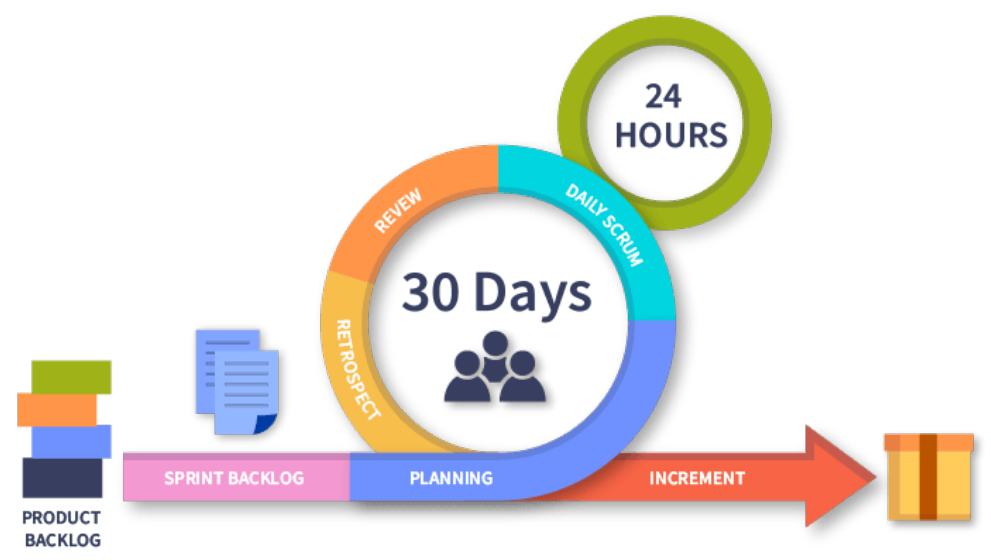

Fig. 1. The Scrum Process

Fig 1. Presents conceptualize the Scrum process. In a nutshell, the first stage is the Product backlog, where the process of requirements is carried out by listing the order according to the respective scale. At this stage, a needs analysis of the virtual reality game system will be carried out. The sprint backlog is a list of tasks the Scrum team has identified to complete during project development. The team will recount several product backlog items, and identify the tasks required to improve each user story. Sprint planning is the defined stages duration of time to reach the target system completion. A daily scrum is stand-up meetings are the main purposeful method of communication to synchronize activities between team development. The review meeting is the stage of demonstrating system improvement in a single print period all of which were completed in prescribed times[51][52]. The Sprint Retrospective is an opportunity for the Scrum Team to work on it activities and plan for improvements to be made during the next Sprint. It takes after the Sprint Review and before the Sprint Planning. The final stage is increment which is the sum of all Product Backlog items at this stage all sprints must be completed and the product in a state of use to support empiricism at the end of the sprint regardless of and looking forward to stakeholders' approval. 


\section{$4 \quad$ Research Methodology}

\subsection{Scrum development of virtual reality system}

This section will discuss the research methods and how the research steps are carried out. The method used in designing this system is the Scrum method is a software development framework for managing system development. A scrum is a flexible and holistic software development framework in which development teams work as a unit to achieve goals. The scrum method supports teams to help themselves by encouraging close online collaboration from all teams.[53][54], The advantage of using the Scrum method is that scrum can help teams complete project deliverables quickly and efficiency. The process is from each iteration, requirement, product backlog, sprint, development and approval. This stage is represented graphically in Fig 2. The challenges will inevitably occur in this software development process. Thus, a method is needed that can adapt to needs easily to assist in a predictive or planned advantage. The selection of the right methodology will affect the success of a project[55][56]. This game application is fairly complex that there will inevitably be some changes in needs during the system development process. These changes are certainly quite difficult to accommodate if using traditional methods. For example, waterfall method does not determine how to respond unexpected output from one of the development processes on the system[57].

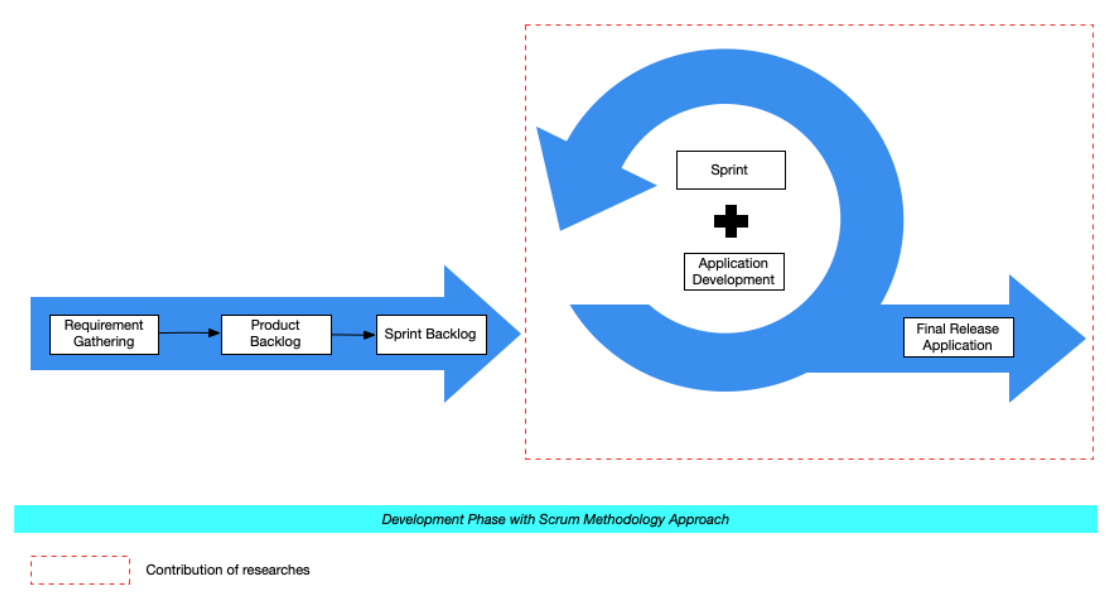

Fig. 2. Development Phase with Scrum Methodology Approach

At the Fig 2. Uses a workflow to describe the research activities of the Virtual Reality application development team using Scrum. The scrum model proposed in this study is a combination of several stages of application development that focuses on the virtual reality mobile application system development model. 
At the Fig 3. The first stage of two activities carried out in parallel (1) is the Requirement Gathering, where at the stage the researcher collects data and the need to support how the mobile virtual reality application will be built, starting from presenting background knowledge about the subject, business processes, roles, what is needed from the user for this virtual reality mobile app. (2) Analyse a list of what to do with a product. There is an order from the first until the end. At this stage, it will classify the necessary in building applications that have been generated from the previous gathering process, this is called the backlog item which consists of a list of features and products that must be completed, sorted according to priority scale. Furthermore, the following research activities are completed sequentially: (3) Starting from several sprint stages of developing the application. There are four sprints, the first activities are carried out starting with the storyboard, which is to make a set of sketched images arranged in a sequence that is adjusted to the idea of a game-making flow so that the story and learning material to be delivered can be accepted easily. After that, proceed with preparing a library of assets for visual words and creating an animation model design.

The second sprint a GUI was made which functions to make it easier for users to use virtual reality applications, through graphic images, icons, menus, and to beautify the appearance of an application and continued by collecting all the data to complete the application with various elements such as back sound, audio and others.

The third sprint exported data to the library and built the game level into several levels starting from easy, medium and hard, and debugging tests were carried out to find out whether the features worked as expected and there are several combined sprints on how to formulate the sprint stage with the application development process to build mobile virtual reality applications. In this phase, teams work together and conduct a stand-up which is called the weekly Scrum Meeting. If an error were found, it will try to remove all known obstacles and what efforts are made to resolve the problem.

The fourth sprint is the development of an application that will start using the $\mathrm{C} \#$ programming language for object-oriented data processing which provides high flexibility in easy program customization. In addition, it takes two stages of testing, there are the deficiency testing system and the validity system. A deficiency test is conducted to find deficiencies in the system and if the testing is successful the system was completed. The system validity test is to see the extent to which the system can show the validity of an instrument that refers to carrying out functions in the system. In this application development process, each one is completed the sprint phase will be checked is carried out if the application is accepted by the stakeholder then the application will be built, if not then repairs will be created as requested. At the end of the sprint, the team presents the developed features to the team and other stakeholders, which can potentially be released, this took one month to complete. 


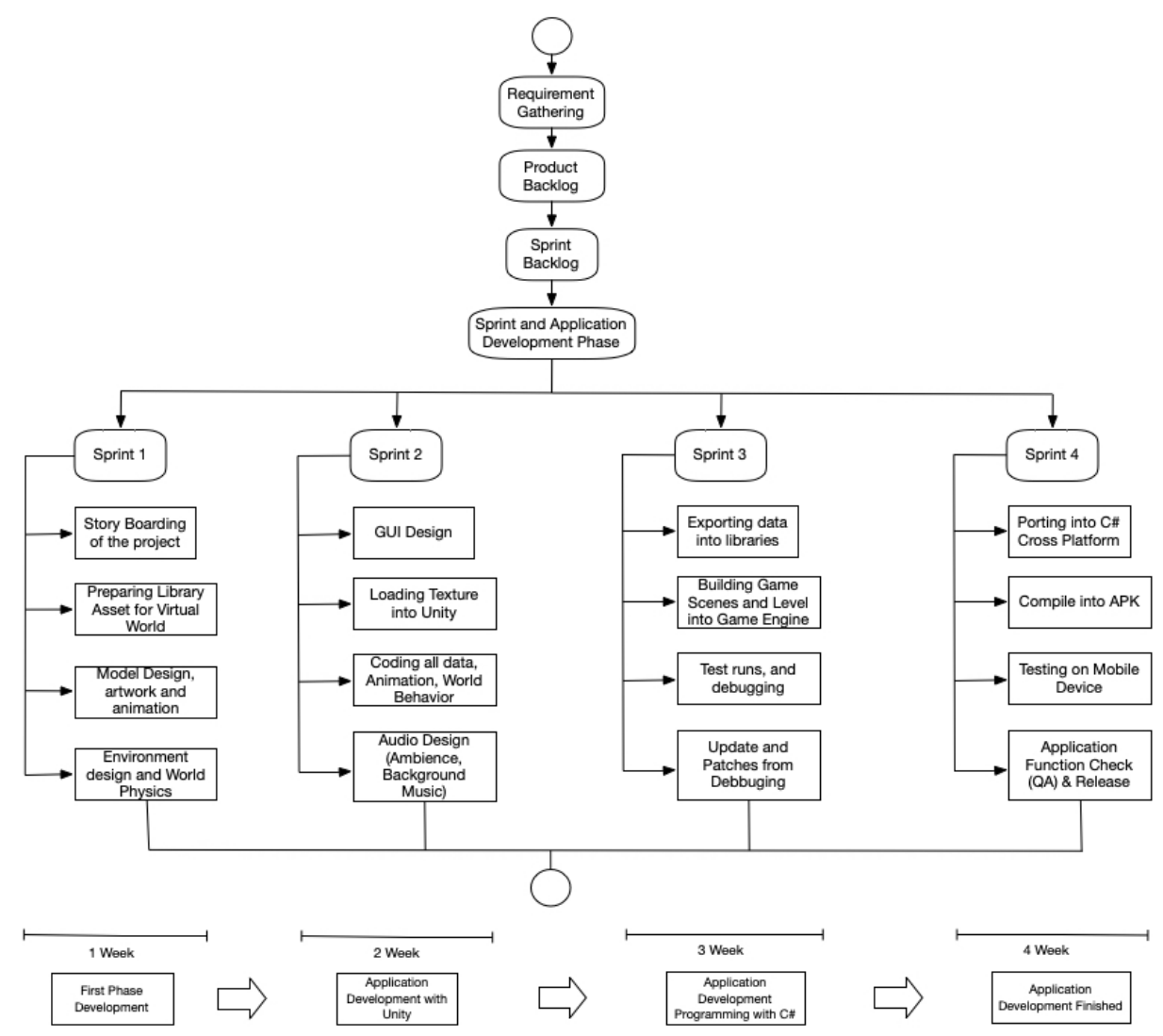

Fig. 3. Game Development with Scrum

Sprint is an iterative cycle that is developed or improved to produce new innovations, usually starting with a planning meeting where the team must complete a list of existing tasks to be performed by the end of the period[58][59]. There are many of the processes in the sprint phase are unidentified or uncontrolled[57]. Therefore, it is treated as a black box that requires external control as a management project to become a reference for the types of work in software development Virtual reality game applications in the form of sprints[60]. Thus control, including risk management, is carried out at each iteration of a predetermined Sprint phase to avoid chaos while maximizing flexibility in developing the final product. 


\section{Mobile Application of Virtual Reality Result}

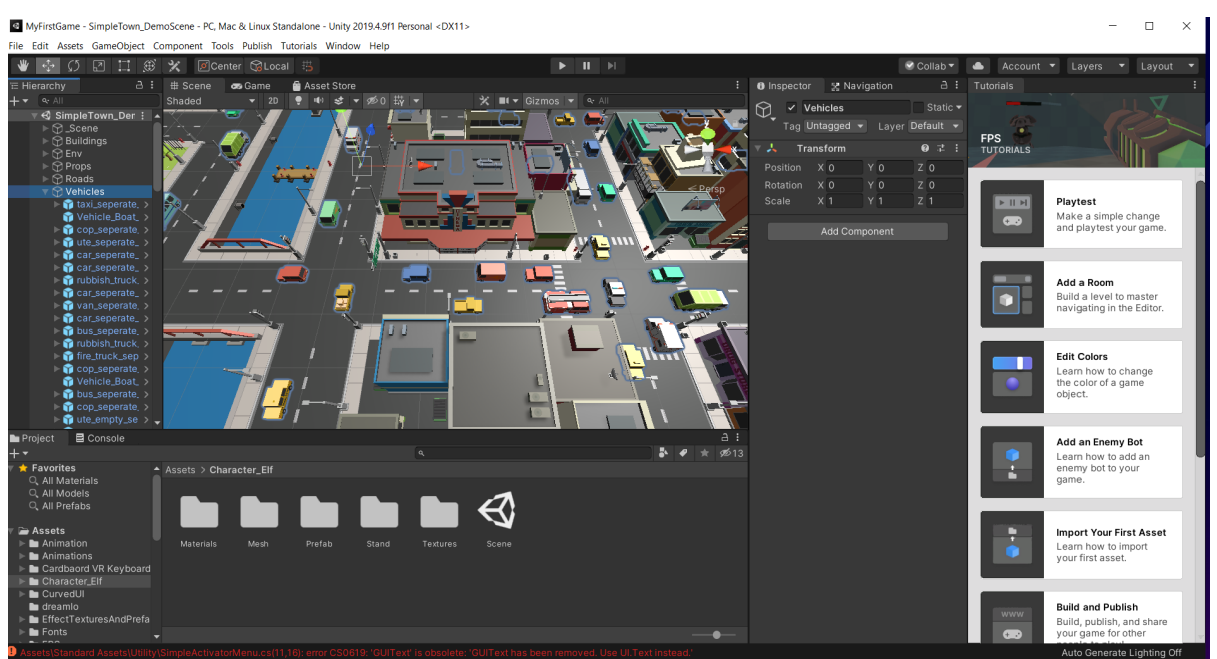

Fig. 4. Game 3D Modelling with Unity

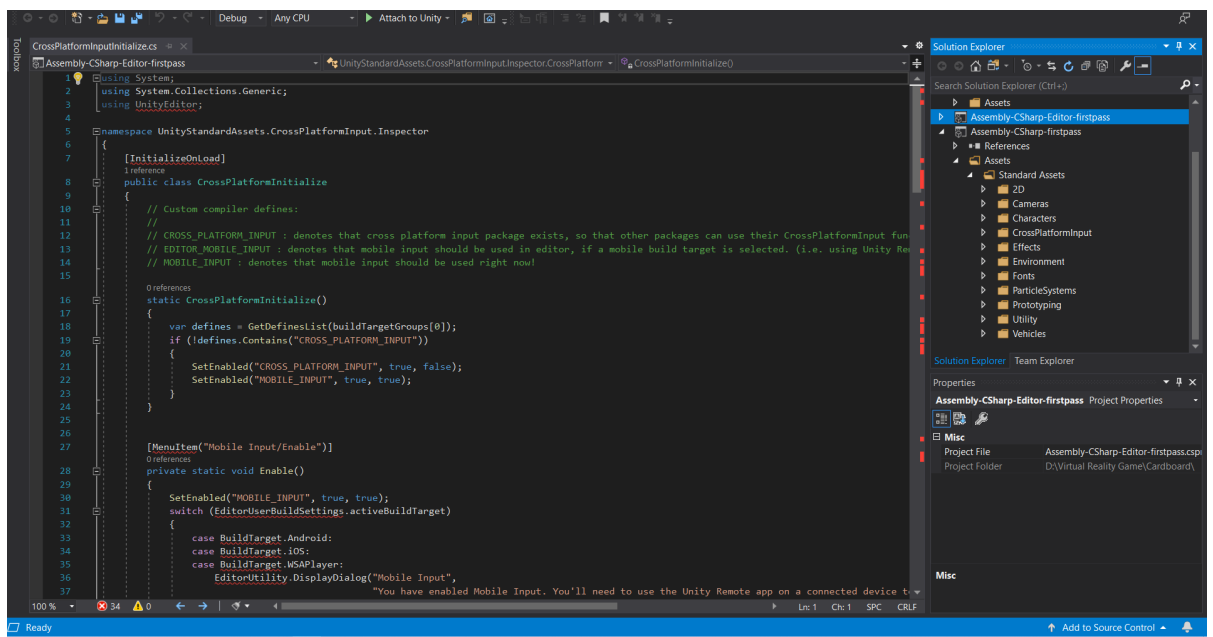

Fig. 5. Game Coding with Assembly C\# 


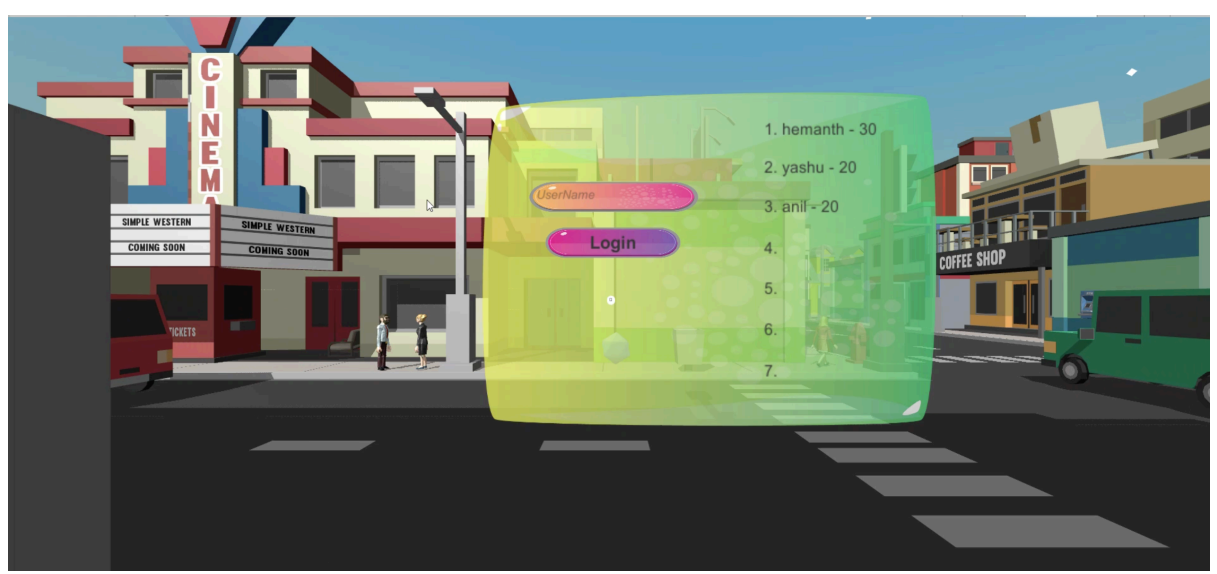

Fig. 6. Start \& LeaderBoard

The main menu interface that will be displayed for students to create a login form by enter the name.

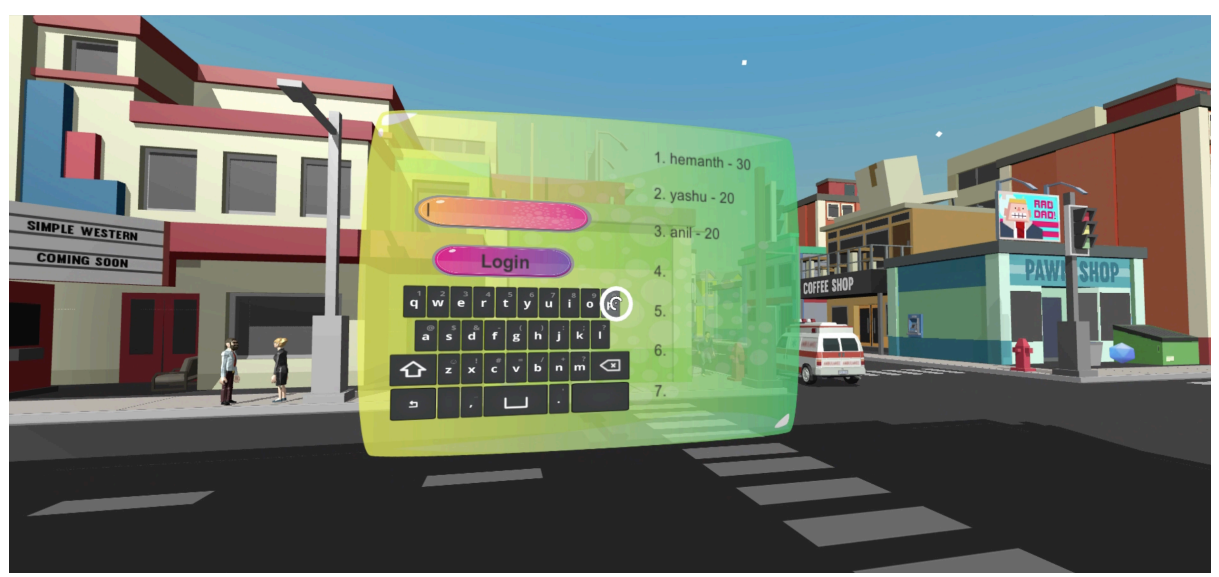

Fig. 7. Input Player Name

After entering the user name, the next interface is to choose a game level starting from easy, medium, hard and free play mode. 


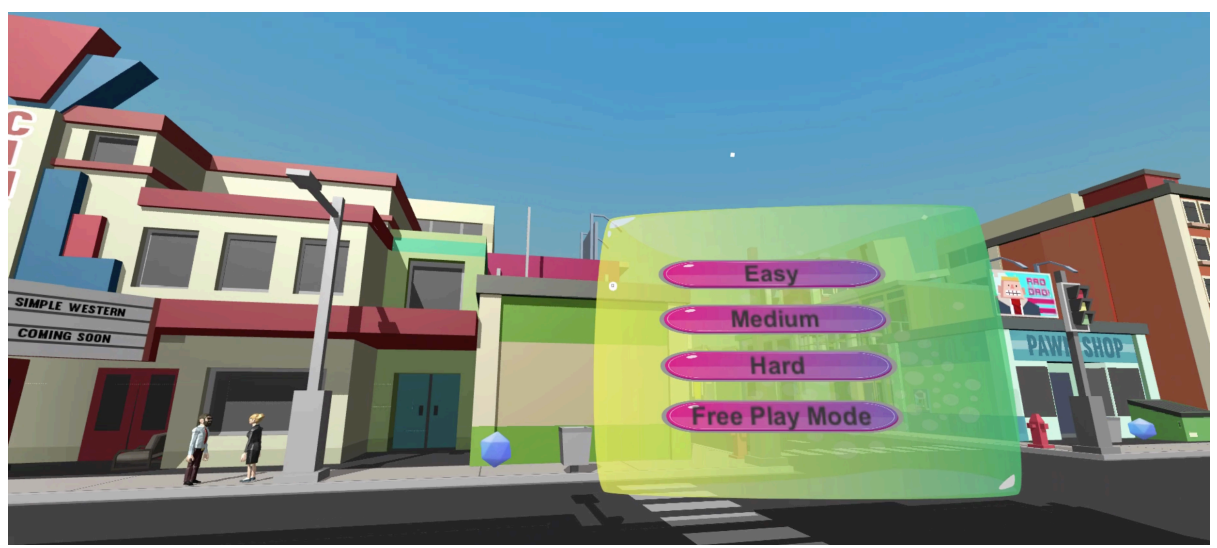

Fig. 8. Choose Game Level

After students choose the level in the game, the next interface is a virtual world image that will take the user to explore virtually to find English practice questions.

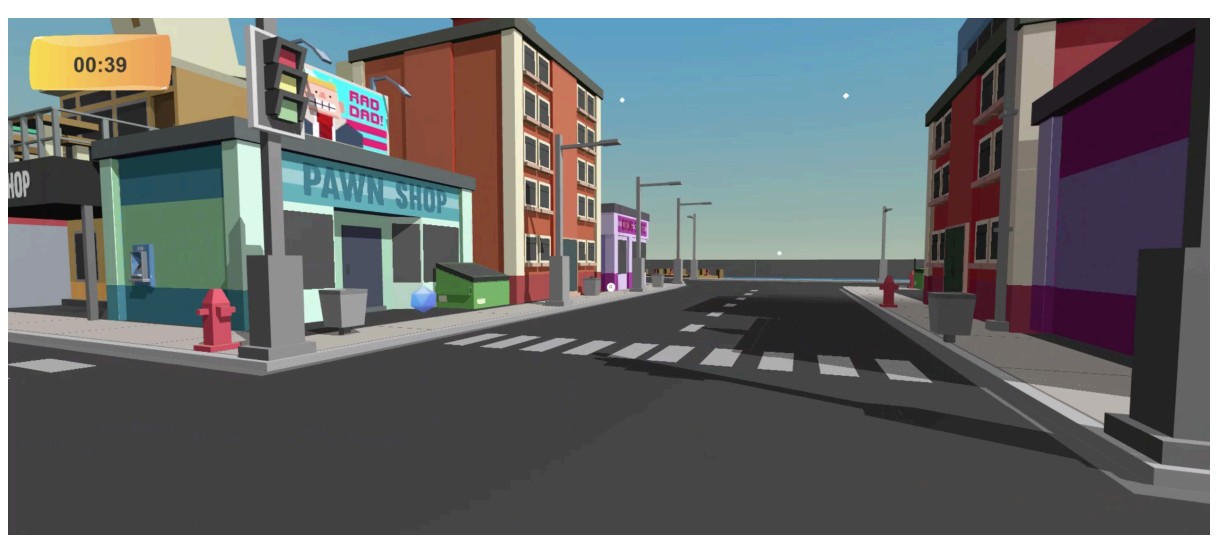

Fig. 9. Virtual World

After that, the students will find a question in the middle of the game that must be answered with predetermined time duration, the vehicle will continue to drive according to the direction of the player. 


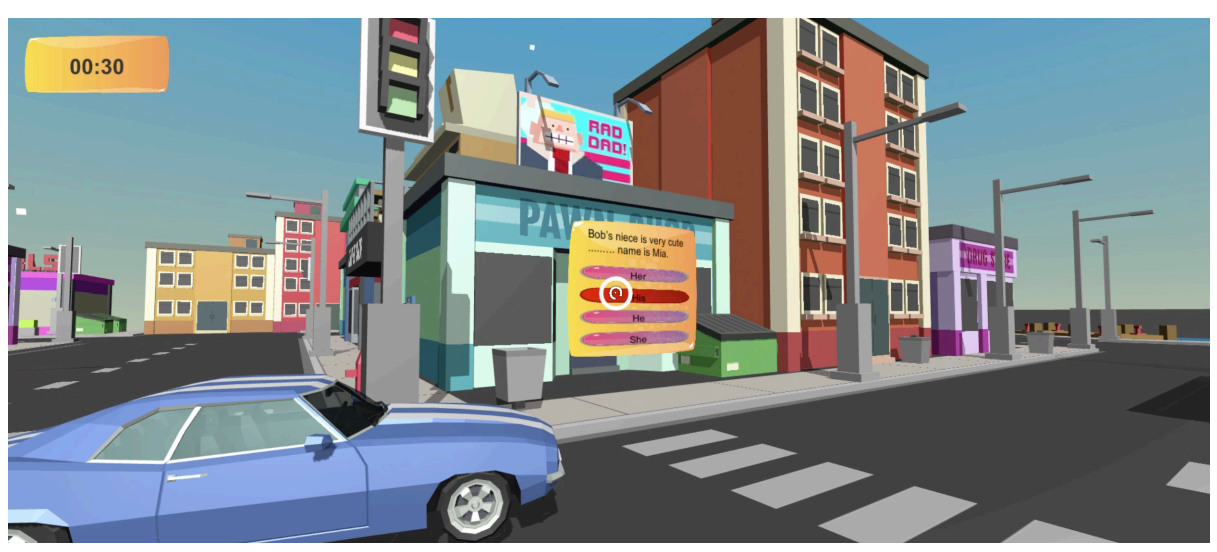

Fig. 10.Answer Question

Then, if the students have successfully answered the questions, the students will be taken to explore to find the next questions.

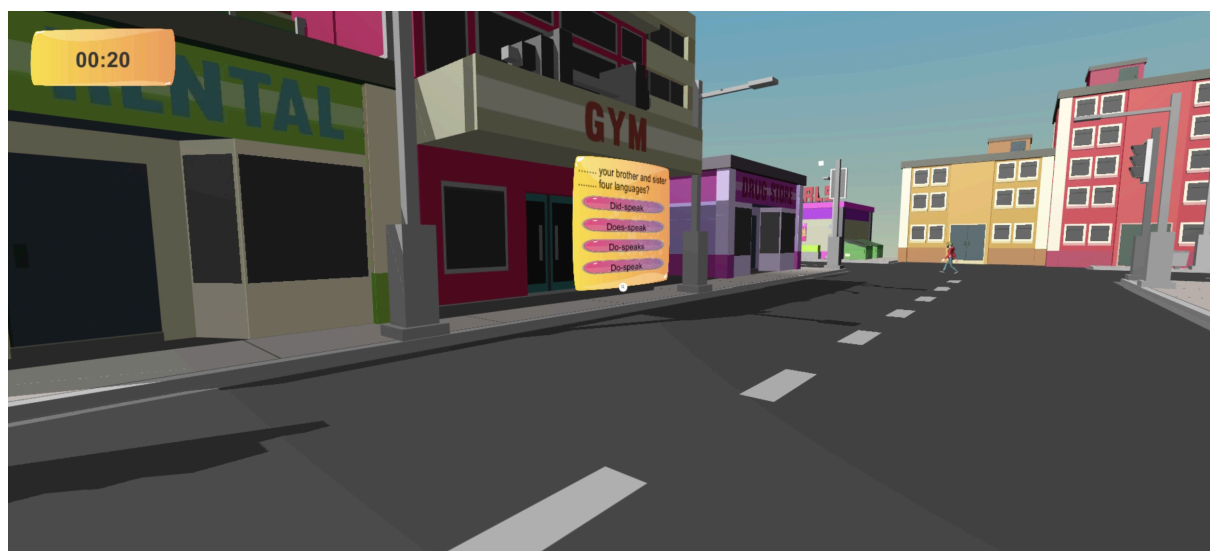

Fig. 11.Answer Question 2

If the student has completed the mission to answer all the questions encountered in the game within the specified time, then the score will appear at the end of the adventure. 


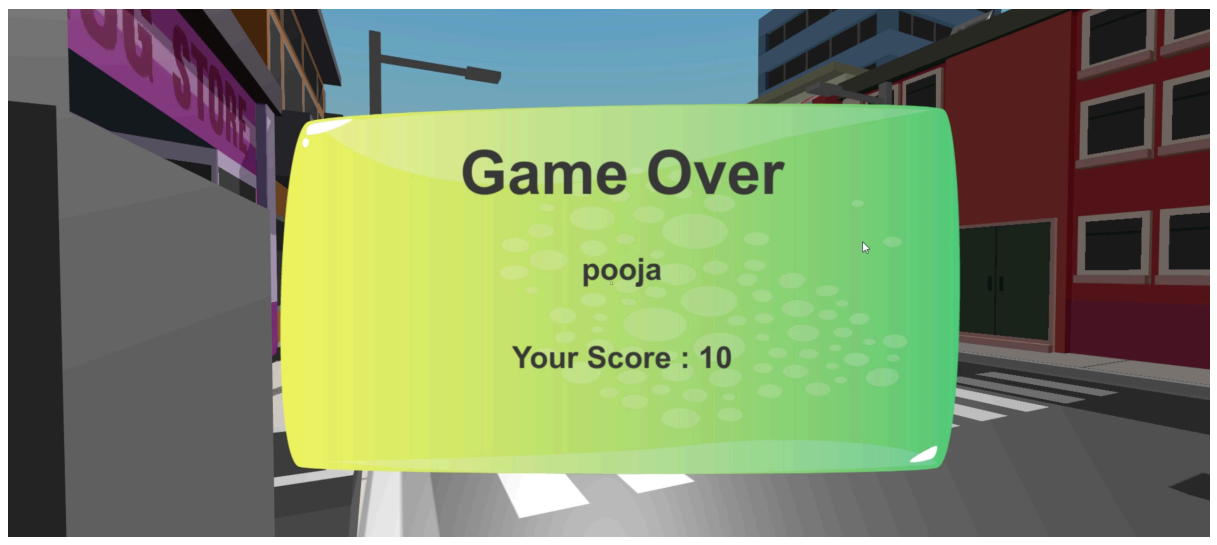

Fig. 12.End of Game-Score

The interface will display the name of the student or user along with the score obtained.

\section{Conclusion}

This study is contributes to the development of mobile-based applications by using scrum as a guideline in building Virtual Reality applications in education as a new medium in learning English for students. Overall, the findings indicate that Sprint planning in Scrum helps to overcome multiple levels of abstraction, specifically in feedback from game testers helping developers to move abstract game concepts to concrete reality from playable versions of virtual reality games then reinforcing the flexibility and adaptability of Sprint planning in learning what user experiences are desired has materialized, and then find more opportunities to improve game features in the next iteration that will add to the quality of the game. One limitation of this study is that Scrum has limitations such as light documentation and is not suitable for large-scale projects. Besides scrum is usually implemented by people who has been expertly[48].

\section{$7 \quad$ References}

[1] C. Mann and F. Maurer, "A case study on the impact of scrum on overtime and customer satisfaction," Proc. - Agil. Confernce 2005, vol. 2005, no. August 2005, pp. 70-79, 2005.

[2] K. Vlaanderen, S. Jansen, S. Brinkkemper, and E. Jaspers, "The agile requirements refinery: Applying SCRUM principles to software product management," Inf. Softw. Technol., vol. 53, no. 1, pp. 58-70, 2011. https://doi.org/10.1016/j.infsof.2010.08.004

[3] S. Papadakis, J. Vaiopoulou, M. Kalogiannakis, and D. Stamovlasis, "Developing and exploring an evaluation tool for educational apps (E.T.E.A.) targeting kindergarten children," Sustain., vol. 12, no. 10, pp. 1-10, 2020. https://doi.org/10.3390/su12104201 
[4] D. Kamińska et al., "Virtual reality and its applications in education: Survey," Inf., vol. 10, no. 10, pp. 1-20, 2019. https://doi.org/10.3390/info10100318

[5] S. Papadakis, M. Kalogiannakis, and N. Zaranis, "Educational apps from the Android Google Play for Greek preschoolers: A systematic review," Comput. Educ., vol. 116, pp. 139-160, 2018. https://doi.org/10.1016/i.compedu.2017.09.007

[6] S. Papadakis, N. Zaranis, and M. Kalogiannakis, "Parental involvement and attitudes towards young Greek children's mobile usage," Int. J. Child-Computer Interact., vol. 22, no. xxxx, p. 100144, 2019. https://doi.org/10.1016/j.ijcci.2019.100144

[7] S. Papadakis, "Tools for evaluating educational apps for young children: a systematic review of the literature," Interact. Technol. Smart Educ., 2020. https://doi.org/10.1108/ITSE08-2020-0127

[8] C. Troussas, A. Krouska, and C. Sgouropoulou, "Collaboration and fuzzy-modeled personalization for mobile game-based learning in higher education," Comput. Educ., vol. 144, no. September 2019, p. 103698, 2020. https://doi.org/10.1016/j.compedu.2019.103698

[9] B. Gao, Q. Q. Wan, T. W. Chang, and R. Huang, "A Framework of Learning Activity Design for Flow Experience in Smart Learning Environment," Lect. Notes Educ. Technol., pp. 5-14, 2019. https://doi.org/10.1007/978-981-13-6908-7 2

[10] D. Siegle, "Seeing Is Believing: Using Virtual and Augmented Reality to Enhance Student Learning," Gift. Child Today, vol. 42, no. 1, pp. 46-52, 2019. https://doi.org/10.1177/ $\underline{1076217518804854}$

[11] M. Drolia, E. Sifaki, and S. Papadakis, "An Overview of Mobile Learning for Refugee Students : Juxtaposing Refugee Needs with Mobile Applications ' Characteristics," 2020. https://doi.org/10.3390/challe11020031

[12] P. Dorouka, S. Papadakis, and M. Kalogiannakis, "Tablets and apps for promoting robotics, mathematics, STEM education and literacy in early childhood education," Int. J. Mob. Learn. Organ., vol. 14, no. 2, pp. 255-274, 2020. https://doi.org/10.1504/IJMLO.2020. 106179

[13] J. M. Zydney and Z. Warner, "Mobile apps for science learning: Review of research," Comput. Educ., vol. 94, pp. 1-17, 2016. https://doi.org/10.1016/j.compedu.2015.11.001

[14] L. S. Green, R. P. Hechter, P. D. Tysinger, and K. D. Chassereau, "Mobile app selection for 5th through 12th grade science: The development of the MASS rubric," Comput. Educ., vol. 75, pp. 65-71, 2014. https://doi.org/10.1016/j.compedu.2014.02.007

[15] J. Kacetl and B. Klímová, "Use of smartphone applications in english language learning-A challenge for foreign language education," Educ. Sci., vol. 9, no. 3, pp. 1-9, 2019. https://doi.org/10.3390/educsci9030179

[16] M. M. Elaish, L. Shuib, N. Abdul Ghani, E. Yadegaridehkordi, and M. Alaa, "Mobile Learning for English Language Acquisition: Taxonomy, Challenges, and Recommendations," IEEE Access, vol. 5, no. September, pp. 19033-19047, 2017. https://doi.org/10.1109/ACCESS.2017.2749541

[17] L. Freina and M. Ott, "A literature review on immersive virtual reality in education: State of the art and perspectives," Proc. eLearning Softw. Educ. (eLSE)(Bucharest, Rom. April 23--24, 2015), no. July, p. 8, 2015.

[18] M. Yilmaz, "Encyclopedia of Computer Graphics and Games," Encycl. Comput. Graph. Games, no. December 2017, 2020.

[19] D. Friis, J. Ostergaard, and J. Sutherland, "Virtual reality meets scrum: How a senior team moved from management to leadership," Proc. Annu. Hawaii Int. Conf. Syst. Sci., 2011. https://doi.org/10.1109/HICSS.2011.483

[20] N. V. Papulovskaya and L. G. Dorosinskiy, "Features of virtual reality systems development," CEUR Workshop Proc., vol. 2562, pp. 205-210, 2019. 
[21] B. Han and J. Xie, "Practical Experience: Adopt Agile Methodology Combined With Kanban For Virtual Reality Development," no. May, 2012.

[22] D. Velev and P. Zlateva, "Virtual Reality Challenges in Education and Training," Int. J. Learn. Teach., vol. 3, no. 1, pp. 33-37, 2017. https://doi.org/10.18178/ijlt.3.1.33-37

[23] J. H. B. Soto, D. C. T. Ocampo, L. del Carmen Beltrán Colón, and A. V. Oropesa, "Perceptions of immerseme virtual reality platform to improve english communicative skills in higher education," Int. J. Interact. Mob. Technol., vol. 14, no. 7, pp. 4-19, 2020. https://doi.org/10.3991/ijim.v14i07.12181

[24] X. Yang, L. Lin, P. Y. Cheng, X. Yang, Y. Ren, and Y. M. Huang, "Examining creativity through a virtual reality support system," Educ. Technol. Res. Dev., vol. 66, no. 5, pp. 1231-1254, 2018. https://doi.org/10.1007/s11423-018-9604-z

[25] S. M. Cochran, C. A. Aiken, C. K. Rhea, and L. D. Raisbeck, "Human Movement Science Effects of an external focus of attention and target occlusion on performance in virtual reality," Hum. Mov. Sci., vol. 76, no. November 2020, p. 102753, 2021. https://doi.org/ 10.1016/j.humov.2021.102753

[26] J. Martín-Gutiérrez, C. E. Mora, B. Añorbe-Díaz, and A. González-Marrero, "Virtual technologies trends in education," Eurasia J. Math. Sci. Technol. Educ., vol. 13, no. 2, pp. 469486, 2017. https://doi.org/10.12973/eurasia.2017.00626a

[27] Y. L. Chen and C. C. Hsu, "Self-regulated mobile game-based English learning in a virtual reality environment," Comput. Educ., vol. 154, no. October 2019, p. 103910, 2020. https://doi.org/10.1016/j.compedu.2020.103910

[28] A. Mueangpud, J. Khlaisang, and P. Koraneekij, "Mobile learning application design to promote youth financial management competency in Thailand," Int. J. Interact. Mob. Technol., vol. 13, no. 12, pp. 19-38, 2019. https://doi.org/10.3991/ijim.v13i12.11367

[29] A. Sönmez, L. Göçmez, D. Uygun, and M. Ataizi, "A review of Current Studies of Mobile Learning," J. Educ. Technol. Online Learn., vol. 1, no. 1, pp. 12-27, 2018. https://doi.org/ $10.31681 /$ jetol.378241

[30] M. Abbas, G. Hwang, S. Ajayi, and G. Mustafa, "Computers and Education : Arti fi cial Intelligence Modelling and exploiting taxonomic knowledge for developing mobile learning systems to enhance children ' s structural and functional categorization," Comput. Educ. Artif. Intell., vol. 2, no. October 2020, p. 100007, 2021. https://doi.org/10.1016/ j.caeai.2021.100007

[31] M. Elkhateeb, A. Shehab, and H. El-Bakry, "Mobile learning system for egyptian higher education using agile-based approach," Educ. Res. Int., vol. 2019, 2019. https://doi.org/ $10.1155 / 2019 / 7531980$

[32] J. Radianti, T. A. Majchrzak, J. Fromm, and I. Wohlgenannt, "A systematic review of immersive virtual reality applications for higher education: Design elements, lessons learned, and research agenda," Comput. Educ., vol. 147, no. November 2019, p. 103778, 2020. https://doi.org/10.1016/j.compedu.2019.103778

[33] C. Haythornthwaite and R. Andrews, "Introduction to E-learning research," no. January, 2007.

[34] A. Saeed, L. Foaud, and L. Fattouh, "Environments and System Types of Virtual Reality Technology in STEM: a Survey," Int. J. Adv. Comput. Sci. Appl., vol. 8, no. 6, 2017. https://doi.org/10.14569/IJACSA.2017.080610

[35] N. A. Zaini, S. F. M. Noor, and T. S. M. T. Wook, "The model of Game-Based Learning in fire safety for preschool children," Int. J. Adv. Comput. Sci. Appl., vol. 10, no. 9, pp. 167$175,2019$. 
[36] M. J. Maas and J. M. Hughes, "Virtual, augmented and mixed reality in K-12 education: a review of the literature," Technol. Pedagog. Educ., vol. 29, no. 2, pp. 231-249, 2020. https://doi.org/10.1080/1475939X.2020.1737210

[37] H. Serin, "Virtual Reality in Education from the Perspective of Teachers," Rev. Amaz. Investig., vol. 9, no. 26, pp. 291-303, 2020. https://doi.org/10.34069/AI/2020.26.02.33

[38] B. I. Fox and B. G. Felkey, "Virtual reality and pharmacy: Opportunities and challenges," Hosp. Pharm., vol. 52, no. 2, pp. 160-161, 2017. https://doi.org/10.1310/hpj5202-160

[39] C. Li and B. Tang, "Research on the Application of AR Technology Based on Unity3D in Education," J. Phys. Conf. Ser., vol. 1168, no. 3, 2019. https://doi.org/10.1088/17426596/1168/3/032045

[40] T. Tahirović, T. Naumović, L. Živojinović, Z. Bogdanović, and M. Despotović-Zrakić, "Designing Augmented Reality Services for E-Business: A Project Management Perspective," Eur. Proj. Manag. J., vol. 8, no. 2, pp. 9-16, 2018. https://doi.org/10.18485/epmj.2018.8.2.2

[41] X. Liu, Y.-H. Sohn, and D.-W. Park, "Application development with vuforia and unity 3D," Int. J. Appl. Eng. Res., vol. 13, no. 21, p. 43, 2018.

[42] O. Halabi, "Immersive virtual reality to enforce teaching in engineering education," Multimed. Tools Appl., vol. 79, no. 3-4, pp. 2987-3004, 2020. https://doi.org/10.1007/s11042$\underline{019-08214-8}$

[43] A. H. Odeh, "Analytical and comparison study of main web programming languages-ASP and PHP," TEM J., vol. 8, no. 4, pp. 1517-1522, 2019.

[44] H. Vu, "From C to C ++, C \#, and Java," Int. J. Sci. Res. Innov. Technol., vol. 2, no. 2, pp. 84-92, 2015.

[45] X. Li, D. Liu, and X. Zhang, "A System Integrated with C\# Programing and Real-Time 3D Observation for Learning Virtual Reality Technology," Open J. Soc. Sci., vol. 07, no. 03, pp. 127-135, 2019. https://doi.org/10.4236/jss.2019.73009

[46] L. J. Kingsley et al., "Development of a virtual reality platform for effective communication of structural data in drug discovery," J. Mol. Graph. Model., vol. 89, pp. 234-241, 2019. https://doi.org/10.1016/j.jmgm.2019.03.010

[47] J. V. Moniaga, A. Chowanda, A. Prima, Oscar, and M. D. Tri Rizqi, "Facial Expression Recognition as Dynamic Game Balancing System," Procedia Comput. Sci., vol. 135, pp. 361-368, 2018. https://doi.org/10.1016/j.procs.2018.08.185

[48] S. Shafiee, Y. Wautelet, L. Hvam, E. Sandrin, and C. Forza, "Scrum versus Rational Unified Process in facing the main challenges of product configuration systems development," J. Syst. Softw., vol. 170, p. 110732, 2020. https://doi.org/10.1016/j.jss.2020.110732

[49] S. Chaouch, A. Mejri, and S. A. Ghannouchi, "A framework for risk management in Scrum development process," Procedia Comput. Sci., vol. 164, pp. 187-192, 2019. https://doi.org/10.1016/j.procs.2019.12.171

[50] S. Ashraf and S. Aftab, "Pragmatic Evaluation of IScrum \& Scrum," Int. J. Mod. Educ. Comput. Sci., vol. 10, no. 1, pp. 24-35, 2018. https://doi.org/10.5815/ijmecs.2018.01.03

[51] R. S. Kenett, "Implementing SCRUM using Business Process Management and Pattern Analysis Methodologies," Dyn. Relationships Manag. J., vol. 2, no. 2, pp. 29-48, 2013. https://doi.org/10.17708/DRMJ.2013.v02n02a03

[52] J. W. Liu, C. Y. Ho, J. Y. T. Chang, and J. C. A. Tsai, "The role of Sprint planning and feedback in game development projects: Implications for game quality," J. Syst. Softw., vol. 154, pp. 79-91, 2019. https://doi.org/10.1016/j.jss.2019.04.057

[53] S. Sachdeva, "Scrum Methodology," Int. J. Eng. Comput. Sci., vol. 5, no. 16792, pp. 16792-16800, 2016. 
[54] H. Lei, F. Ganjeizadeh, P. K. Jayachandran, and P. Ozcan, "A statistical analysis of the effects of Scrum and Kanban on software development projects," Robot. Comput. Integr. Manuf., vol. 43, pp. 59-67, 2017. https://doi.org/10.1016/j.rcim.2015.12.001

[55] R. Joslin and R. Müller, "The impact of project methodologies on project success in different project environments," Int. J. Manag. Proj. Bus., vol. 9, no. 2, pp. 364-388, 2016. https://doi.org/10.1108/IJMPB-03-2015-0025

[56] P. Nidagundi and L. Novickis, "Introducing Lean Canvas Model Adaptation in the Scrum Software Testing," Procedia Comput. Sci., vol. 104, no. December 2016, pp. 97-103, 2016. https://doi.org/10.1016/j.procs.2017.01.078

[57] K. Schwaber, "SCRUM Development Process," Bus. Object Des. Implement., no. April 1987, pp. 117-134, 1997. https://doi.org/10.1007/978-1-4471-0947-1 11

[58] E. S. Hidalgo, "Adapting the scrum framework for agile project management in science: case study of a distributed research initiative," Heliyon, vol. 5, no. 3, p. e01447, 2019. https://doi.org/10.1016/j.heliyon.2019.e01447

[59] J. Garbett, T. Hartley, and D. Heesom, "A multi-user collaborative BIM-AR system to support design and construction," Autom. Constr., vol. 122, no. July 2019, p. 103487, 2021. https://doi.org/10.1016/j.autcon.2020.103487

[60] J. Vlietland and H. Van Vliet, "Towards a governance framework for chains of Scrum teams," Inf. Softw. Technol., vol. 57, no. 1, pp. 52-65, 2015. https://doi.org/10.1016/ j.infsof.2014.08.008

\section{Authors}

Albert Yakobus Chandra is a lecturer in Information System department, Faculty of Information Technology, Universitas Mercu Buana Yogyakarta. His focus area of research are Software Engineering, Artificial Intelligence, and Computer Network.

Putri Taqwa Prasetyaningrum is a lecturer in Information System department, Faculty of Information Technology, Universitas Mercu Buana Yogyakarta. Her focus area of research are Customer Relationship Management and Enterprise Information System.

Ozzi Suria is a lecturer in Information System department, Faculty of Information Technology, Universitas Mercu Buana Yogyakarta. His focus area of research are Virtual Reality, Soft Computing, and Mobile computing.

Paulus Insap Santosa is a senior lecturer in Electrical Engineering and Information Technology department, Faculty of Engineering, Universitas Gadjah Mada. He undertook his doctoral degree from National University of Singapore in 20002006. His focus area of research is Human Computer Interaction.

Lukito Edi Nugroho is a senior lecturer in Electrical Engineering and Information Technology department, Faculty of Engineering, Universitas Gadjah Mada. He undertook his doctoral degree from School of Computer Science and Software Engineering, Monash University, Australia. His focus area of research are Pervasive Computing, Mobile Computing, Software Engineering, and Computer in Education.

Article submitted 2020-11-19. Resubmitted 2021-01-18. Final acceptance 2021-01-25. Final version published as submitted by the authors. 